\title{
Applying an Artificial Neural Network to Predict Coagulation Capacity of Reactive Dyeing Wastewater by Chitosan
}

\author{
Ha Manh Bui ${ }^{1 *}$, Huong Thi Giang Duong ${ }^{1}$ Cuong Duc Nguyen² \\ 'Department of Environmental Sciences, Sai Gon University, Vietnam \\ ${ }^{2}$ Department of Chemical Technology, Ho Chi Minh City Industry and Trade College, Vietnam
}

Received: 13 September 2015

Accepted: 21 December 2015

\begin{abstract}
Chitosan derived from waste shrimp shells was experimentally evaluated to treat reactive dye (red 24) in aqueous solution. The research was conducted using one-factor-at-a-time experiment design (i.e., $\mathrm{pH}$, reaction time, agitation speeds, initial dye, and chitosan concentration) to investigate dye removal efficiencies by reducing colour and COD parameters. The results obtained by performing Jar-tests indicated that prepared chitosan successfully removed the reactive dye in aqueous solution. In particular, $99.5 \%$ of colour and $72.7 \%$ COD removal efficiencies were recorded under neutral conditions ( $\mathrm{pH} 7$ ) with chitosan dosage $80 \mathrm{mg} / \mathrm{L}$ and agitation speed $60 \mathrm{rpm}$ in $30 \mathrm{~min}$. Fourier transform infrared spectra (FTIR) of the chitosan, dye, and formed sludge were also investigated to elucidate the removal mechanism of the dye by chitosan. These indicated the potential of using chitosan as a "green" coagulant to reduce pollutants of textile wastewater. Moreover, three-layer feed-forward artificial neural network (ANN) models were applied to model the coagulation processes with the determination coefficient (R2) 0.986 and the root mean square error (RMSE) 2.951 between predicted and observed outputs. The ANN models were analysed with the connection weight method, neural interpretation diagram, and 3D/contour plots to study the influences of operation factors - both individually and combined - on both colour removal and COD removal process.
\end{abstract}

Keywords: artificial neural network, chitosan, coagulation, reactive red 24, wastewater

\section{Introduction}

The textile industry has a long tradition in Vietnam of contributing $\$ 15$ billion US to the economy in 2013. However, the dyeing process of the textile industry releases a large amount of high organic-polluted, intensely coloured wastewater into the environment [1]. Without suitable

*e-mail: manhhakg@yahoo.com.vn treatment, the wastewater would destroy the natural water environment.

Although most dyeing wastewater treatment plants use biological treatment processes to remove most BOD and some COD parts, colour in textile wastewater which usually comes from dyestuff (the residual pollutant in dyeing wastewater) cannot be completely removed in such processes due to its ability to resist biodegradation $[2,3]$. Therefore, some techniques such as coagulation, adsorption, or advanced oxidation must be added to the biological processes to remove the residual colour in the wastewater. 
Among the techniques mentioned above, coagulation seems to be an effective method to remove remaining dye from textile wastewater. The techniques have been successfully used for dye removal of some kind of textile wastewaters over many years [4]. However, the traditional coagulation process using common coagulants such as alum, ferric chloride, poly aluminium chloride, polyacrylamide, polydiallyl-dimethyl-ammonium chloride, polyacrylic-acid-coacrylamide, etc. seems produce a huge volume of toxic sludge and soluble metal-based or soluble organic polymer-based coagulants that could be a possible link to human cancer or aquatic organisms' harms [5].

Recent studies have focused on a new generation of coagulant - natural based coagulants that are very effective at removing pollutants from many wastewater sources while the coagulants are easily biodegradable and produce low-toxicity sludge $[6,7]$. One of the most popular natural-based coagulants is chitosan, a waste product of shrimp processing that seems to be an effective low-cost coagulant because chitosan usually contains an amount of free amine and hydroxyl groups that could be strongly reactive with pollutant particles $[8,9]$.

Besides the choice of removal techniques, modelling its process is also a critical task. A lot of reports have tried to model the mechanisms involved in the coagulation processes and some of the models are adequate for explaining the phenomenological mechanisms. However, their modelling processes require rich knowledge of coagulation mechanisms and complicated mathematical procedures, without a high coefficient of determination [10-12]. In this way, there is a need for a fast and reliable modelling method to determine the relationships between variables in complex coagulation processes. Recently, numerous researchers have shown that artificial neural networks (ANNs) have been demonstrated to be robust and excellent tools for modeling water treatment processes [13]. This method enables us to understand what happens in a process without actually simulating the physical and chemical laws governing the system [7]. Therefore, we have chosen ANN to model the up-scalingly complex coagulation of textile wastewater. To the best of our knowledge, there has been no research on neural network modelling related to coagulation of textile wastewater by chitosan reported so far.

Our current study attempted to evaluate the dyeremoval capacity of chitosan through colour and COD removal efficiencies using the Jar-test experiment based on five selected parameters, including $\mathrm{pH}$, agitation speed, initial dye concentration (IDC), chitosan dosage, and reaction time. Another attempt is to develop a neural network model that effectively investigates the relationship between the parameters and the dye removal efficiencies of the coagulation process.

\section{Experimental Procedures}

\section{Materials}

\section{Chitosan Stock}

Waste shrimp shells were collected in Ho Chi Minh city, Vietnam, from a local restaurant supplier in August 2014. The preparation of chitosan from these waste shells was prepared according to Luyen [14], and the obtained chitosan was used for the experiment without any purification.

The stock solution of chitosan was prepared by dissolving $2 \mathrm{~g}$ of chitosan in $100 \mathrm{ml}$ of $1 \% \mathrm{HCl}$ acid solution $(20000 \mathrm{mg} / \mathrm{L})$. Then this solution was diluted to the desired mass concentrations (from $100 \mathrm{mg} / \mathrm{L}$ to $350 \mathrm{mg} / \mathrm{L}$ ) before being used.

\section{Reactive Dye Stock}

The commercial Reactive Red 24 (Suncion Red P-2B) was supplied by Oh-Young (a Korean company). The dye was directly used without purification and its characteristics are given in Fig. 1.

One gram of the dye was directly diluted in $1,000 \mathrm{~mL}$ distilled hot water at $\mathrm{pH} 11$ for an hour to get a dye stock

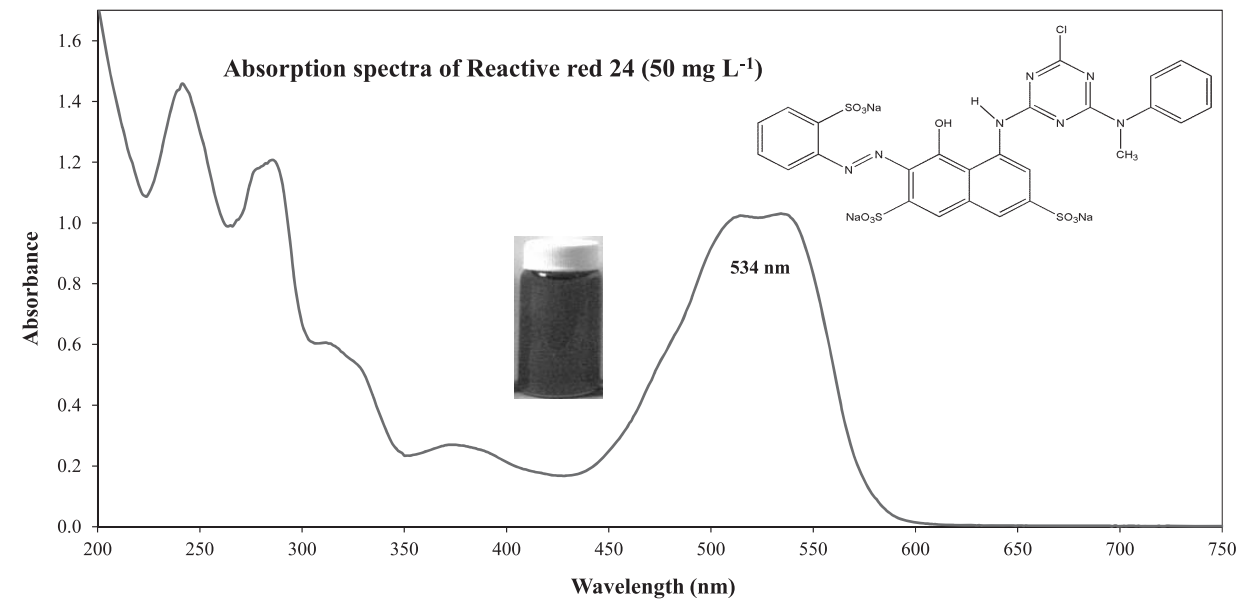

Fig. 1. Chemical structure and spectral properties of Reactive red 24 [3]. 
Table 1. Experimental steps, evaluated factors, and ranges of values for the dye-removing test.

\begin{tabular}{|c|c|c|}
\hline $\begin{array}{c}\text { Experimental } \\
\text { Steps }\end{array}$ & Factor & $\begin{array}{c}\text { Range } \\
\text { of values }\end{array}$ \\
\hline 1 & $\mathrm{pH}$ & $3-12$ \\
\hline 2 & Agitation speed (rpm) & $30-120$ \\
\hline 3 & Reaction time (min) & $15-60$ \\
\hline 4 & Chitosan dosage $(\mathrm{mg} / \mathrm{L})$ & $20-120$ \\
\hline 5 & Initial dye concentration $(\mathrm{mg} / \mathrm{L})$ & $30-140$ \\
\hline
\end{tabular}

solution of $1,000 \mathrm{mg} / \mathrm{L}$ in "hydrolyzed" form. Other dye concentrations, varying between 10 and $140 \mathrm{mg} / \mathrm{L}$, were obtained by diluting this stock.

\section{Decolourization Experiments}

Coagulation studies were conducted using a Jar-test apparatus (Stuart flocculator, SW6) based on the traditional methods described by Ndabigengesere [15], with five factors and their value ranges shown in Table 1 at the initial conditions for the coagulation treatment: chitosan dosage of $100 \mathrm{mg} / \mathrm{L}$, initial dye concentrations (IDC) of $50 \mathrm{mg} / \mathrm{L}$, time (t) of $30 \mathrm{~min}$, and agitation speed (A) of $60 \mathrm{rpm}$. This study was designed based on a one-factor-ata-time experiment carried out by varying one factor while keeping other variables constant.

\section{Artificial Neural Network Model}

A three-layer feed-forward back-propagation network (Fig. 2) was chosen to model the relationship of COD and colour removal efficiencies to five independent variables shown in Table 1. The number of neurons in the hidden layer varied from two to 17 determine the optimal topology of the network. Each topology was repeated 10 times to avoid random correlation due to random initialization of the weights and bias. This network was trained with experimental data using the Bayesian regulation algorithm (trainbr). The experimental data were randomly divided into two groups, i.e., $80 \%$ in the training set and $20 \%$ in the test set. Artificial neural network (ANN) toolbox of Matlab 7.6 mathematical software for Windows was used for training and testing the network on a Pentium Intel core i3, $3.7 \mathrm{GHz}$ computer. To determine the performance of the ANN model, the root of mean square error (RMSE) and the coefficient of determination $\left(\mathrm{R}^{2}\right)$ were used. RMSE represents the errors associated with the model and should be calculated as:

$$
R M S E=\left(\frac{1}{N} \sum_{i=1}^{N}\left(d_{i}-y_{i}\right)^{2}\right)^{\frac{1}{2}}
$$

$\mathrm{R}^{2}$ represents the degree of correlation between the measured and predicted values and can be computed as:

$$
R^{2}=1-\frac{\sum_{i=1}^{N}\left(d_{i}-y_{i}\right)^{2}}{\sum_{i=1}^{N}\left(y_{i}-\bar{y}\right)^{2}}
$$

...where $\mathrm{N}$ is the number of input samples; $y_{i}$ and $d_{i}$ are the observed (actual) value and the desired value obtained from the ANN model correspondent with the $\mathrm{i}^{\text {th }}$ input, respectively; and $\bar{y}$ and $\bar{d}$ are their averages, respectively.

The relative importance of the input variables was also determined according to the connection weight method (Eq. 3) and illustrated by the neural interpretation diagram [16].

$$
V_{i o}=\sum_{j=1}^{h}\left(W_{i j} \times W_{j o}\right)
$$

...where $\mathrm{W}$ is the connection weight value and the superscripts " $i$ " " $j$ " and " $O$ " represent the input, hidden, and output neurons, respectively.

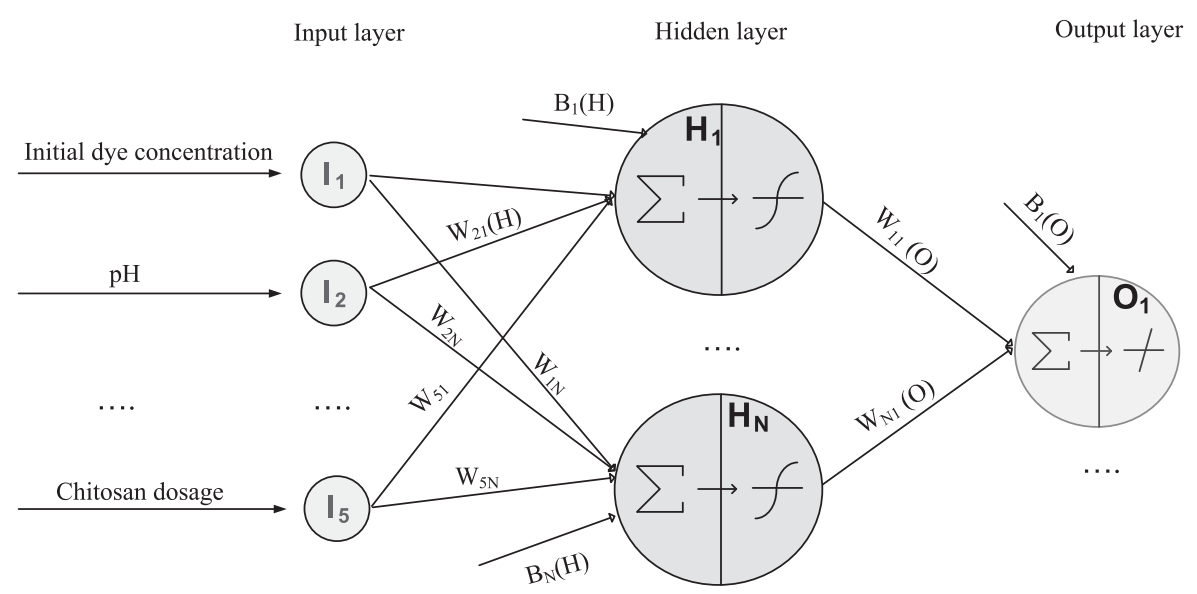

Fig. 2. The three-layer feed-forward neural network. 


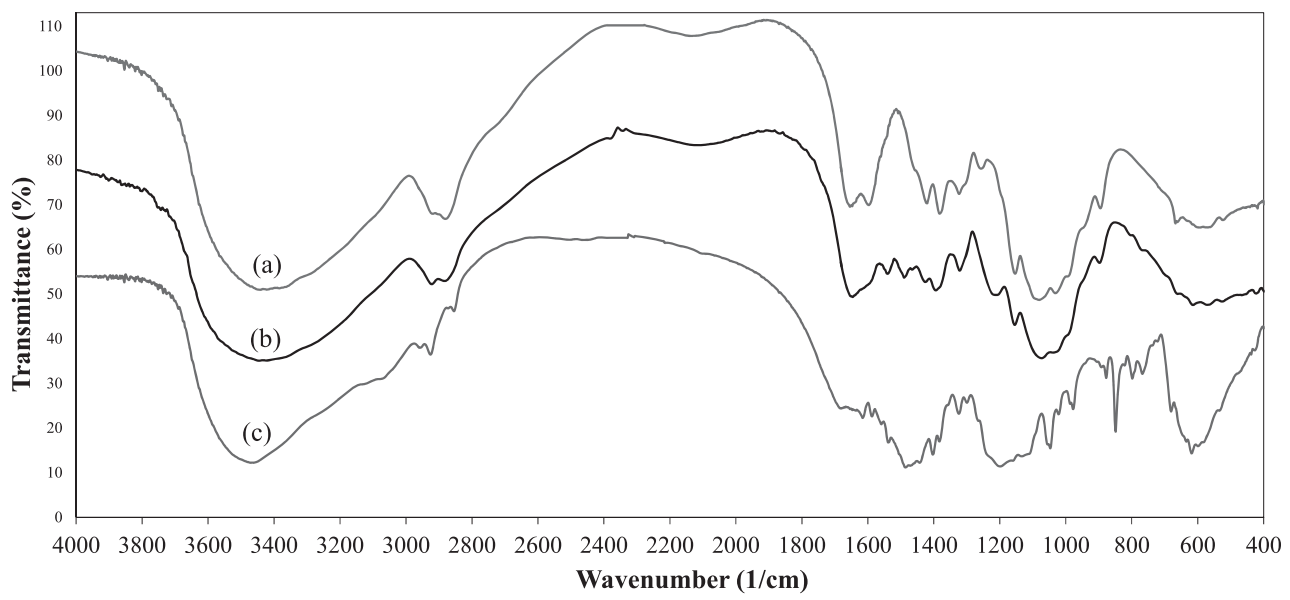

Fig. 3. FTIR spectra of (a) Chitosan, (b) the sludge from chitosan and dye, and (c) pure dye [19].

\section{Analytical Determinations}

The Fourier transform infrared (FTIR) spectra of chitosan and the dye and sludge formed in the coagulation process were analyzed using a Shimadzu FTIR 8400S spectrophotometer in the range between $4000 \mathrm{~cm}^{-1}$ and $400 \mathrm{~cm}^{-1}$ using potassium bromide ( $\mathrm{KBr}$ ) pellets. The degree of deacetylation (\%) of prepared chitosan was calculated based on FTIR spectra according to the Brugnerotto equation [17].

Colour removal efficiency was determined by the percent decrease of maximum absorption (at wavelength 534 nm with an UV-VIS Hach DR 5000 spectrophotometer) in the coagulation process of dye solutions that had been settled after $30 \mathrm{~min}$. Chemical oxygen demand (COD) values of the sample before and after coagulation removal efficiency were determined by the percent decrease of maximum absorption (at wavelength $534 \mathrm{~nm}$ with an UVVIS Hach DR 5000 spectrophotometer) in the coagulation process of dye solutions that had settled after $30 \mathrm{~min}$. COD values of the sample before and after coagulation

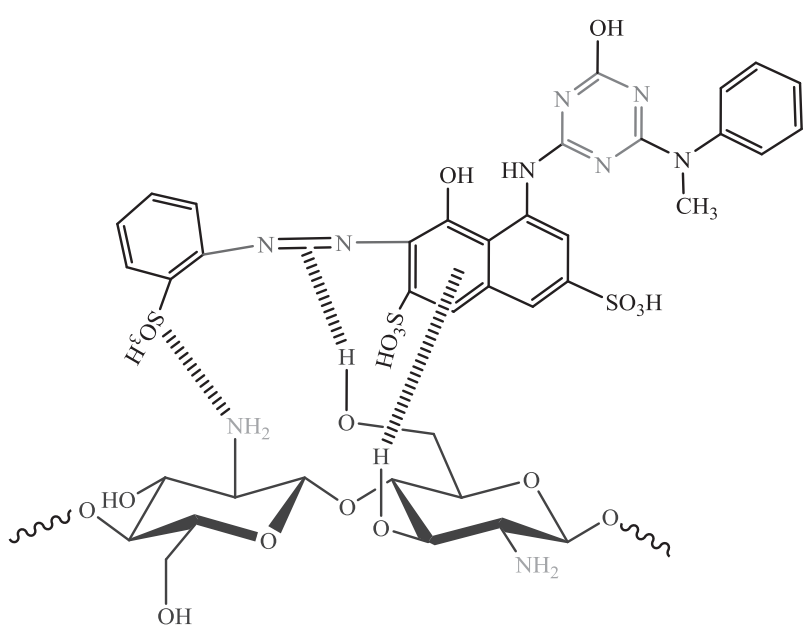

Fig. 4. The hypothetic interaction of chitosan and reactive red 24 [8]. were determined according to the Standard Methods for the Examination of Water and Wastewater [18]. The pH value was determined using a digital $\mathrm{pH}$ meter model 744, Metrohm Ltd. (Switzerland). Each analysis was carried out in duplicate and the results presented here are the average of both \pm standard deviations.

\section{Results and Discussion}

\section{FTIR Studies}

The FTIR spectra of chitosan, dried sludge in the form of coagulation, and the dye are shown in Figs $3(a, b, c)$.

The spectrum of pure chitosan in Fig. 3a shows a broad band at $3,442 \mathrm{~cm}^{-1}$, which is due to the $\mathrm{OH}$ and $\mathrm{NH}_{2}$ stretching. The bands at 2,920 and $2,877 \mathrm{~cm}^{-1}$ correspond to $\mathrm{CH}_{2}$ bending in pyranose ring. While the peak at $1,649 \mathrm{~cm}^{-1}$ can be assigned to $\mathrm{C}=\mathrm{O}$ stretching (amide I) in the acetamide group $(\mathrm{O}=\mathrm{C}-\mathrm{NHR})$, the band at $1,596 \mathrm{~cm}^{-1}$ can be assigned to the NH bending (amide II) $\left(\mathrm{NH}_{2}\right)$. The vibrations of $\mathrm{OH}$ and $\mathrm{CH}$ in the ring of chitosan are also indicated at 1,425 and $1,323 \mathrm{~cm}^{-1}$. The band at $1,159 \mathrm{~cm}^{-1}$ is associated with-C-O-C in glycosidic linkage, while the peaks 1,076 and $1,029 \mathrm{~cm}^{-1}$ are associated with $\mathrm{C}-\mathrm{O}$ stretching in acetamide. The saccharide structure apprears at $898 \mathrm{~cm}^{-1}$. Similar to the chitosan IR spectral, most functional groups on pure dye are revealed in Fig. $3 \mathrm{c}$. The band at $3,460 \mathrm{~cm}^{-1}$ in the spectrum corresponds to $\mathrm{OH}$ and $\mathrm{NH}_{2}$ stretching. Peaks at 3,066 and $848 \mathrm{~cm}^{-1}$ can be assigned to the stretching and bending of the Aryl group, while these peaks at 2,958,2,923, and 2,852 $\mathrm{cm}^{-1}$ can be assigned to $\mathrm{CH}_{2}$ bending. The $\mathrm{C}=\mathrm{C}$ stretching appears at 1,620,1,583, and $1,492 \mathrm{~cm}^{-1}$, while the $\mathrm{N}=\mathrm{N}$ stretching appears at the absorption peak about $1,540 \mathrm{~cm}^{-1}$. For IR absorption in the fingerprint region (below $1,500 \mathrm{~cm}^{-1}$ ), the complex band at around 1,420, 1,326, 1,296 , and $1,049 \mathrm{~cm}^{-1}$ is due to the stretching of sulphonate (R-SO ${ }_{3}^{-}$) groups. Other peaks at 981,767 , and $622 \mathrm{~cm}^{-1}$ correspond to the bending of aromatic compounds and Chlorine. 


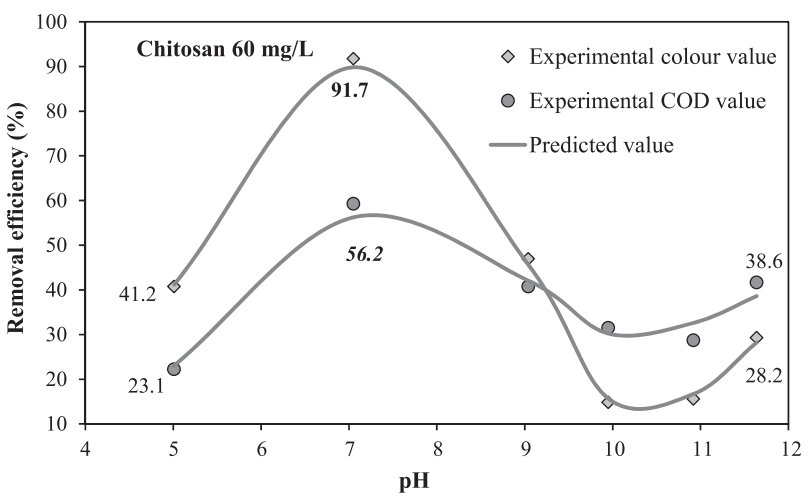

Fig. 5. Influence of $\mathrm{pH}$ on removal efficiencies for the dye using chitosan (IDC $50 \mathrm{mg} / \mathrm{L}, 15 \mathrm{~min}$, and $60 \mathrm{rpm}$ ).

The characteristic features of chitosan and dye spectrum in this study are similar to previous reports $[17,20]$. The spectrum of the sludge formed by chitosan and dye in Fig. $3 b$ shows that the dye was successfully removed by chitosan. Most functional groups on dye such as: aromatic $(\mathrm{CH})$, diazo $(\mathrm{N}=\mathrm{N})$, amide $(\mathrm{N}=\mathrm{C}, \mathrm{CH})$, and sulphonates ( $\left(\mathrm{R}_{-} \mathrm{SO}_{3}{ }^{-}\right)$, etc., disappeared or were strongly diminished. In addition, compared with chitosan spectra (Fig. 3a) the sludge still retains some functional groups such as: amide I, II, and $\mathrm{OH}$ at 1,652, 1,429, and $1,400 \mathrm{~cm}^{-1}$, respectively, but they have lower intensity values of the band. These observations suggest that the reaction mechanism of chitosan and dye is most likely caused by the formation of intermolecular hydrogen bonds between the amino or hydroxyl groups in chitosan and sulphonate or aromatic groups in the dyes as described in the research of Blackburn [8]. Therefore, a proposed linking mechanism of the dye and chitosan is illustrated in Fig. 4.

\section{Coagulation Studies}

The dye removal effects of the prepared chitosan were studied by using a one-factor-at-a-time Jar-test experiment. Herein, the influences of each factor shall be dis-

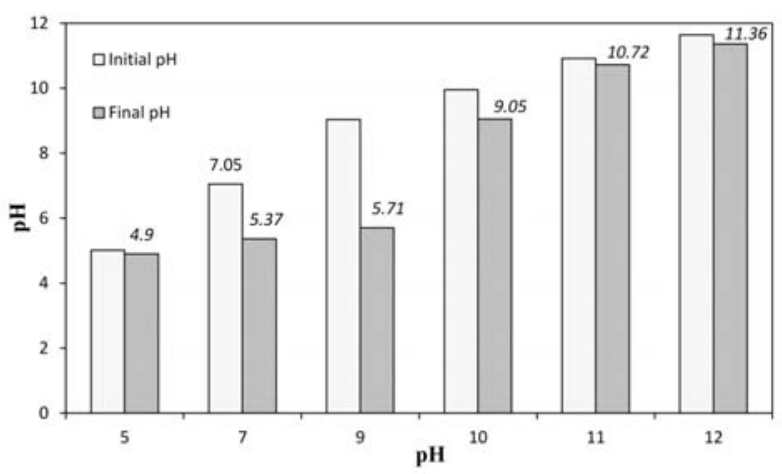

Fig. 6. The change of $\mathrm{pH}$ of red 24 dye solution during the coagulation process.

cussed in the order carried out in the actual experiments.

$$
p H
$$

It has been established that $\mathrm{pH}$ seems to be an important parameter influencing the performance of the dye coagulation process [21-23]. To examine its effect, the sample was adjusted to the desired initial $\mathrm{pH}$ values (i.e. 3, 7, $9,10,11$, and 12) using $0.5 \mathrm{~N} \mathrm{NaOH}$ (or $\mathrm{HCl}$ ) solutions. Other factors were constant, i.e, chitosan dosage $60 \mathrm{mg} / \mathrm{L}$, time contact $15 \mathrm{~min}$, agitation speed $60 \mathrm{rpm}$, and initial dye concentration (IDC) $50 \mathrm{mg} / \mathrm{L}$.

Fig. 5 shows a comparison between experimental values and predicted values of the dye removal efficiencies (COD and colour removal) as a function of the initial $\mathrm{pH}$ with five neurons in the hidden layer. From this plot, it can be seen that obtained results from the proposed ANN model are in good agreement with the experimental data. The maximum removals of the dye at initial $\mathrm{pH} 7$ were 91.7 and $78.8 \%$ for colour and COD removal efficiencies, respectively.

The results were not as expected in $\mathrm{pH}$ around $\mathrm{pH} 5$ [24]. The explanation may come from the possibility of a $\mathrm{pH}$ change in the chitosan solution. As mentioned in the
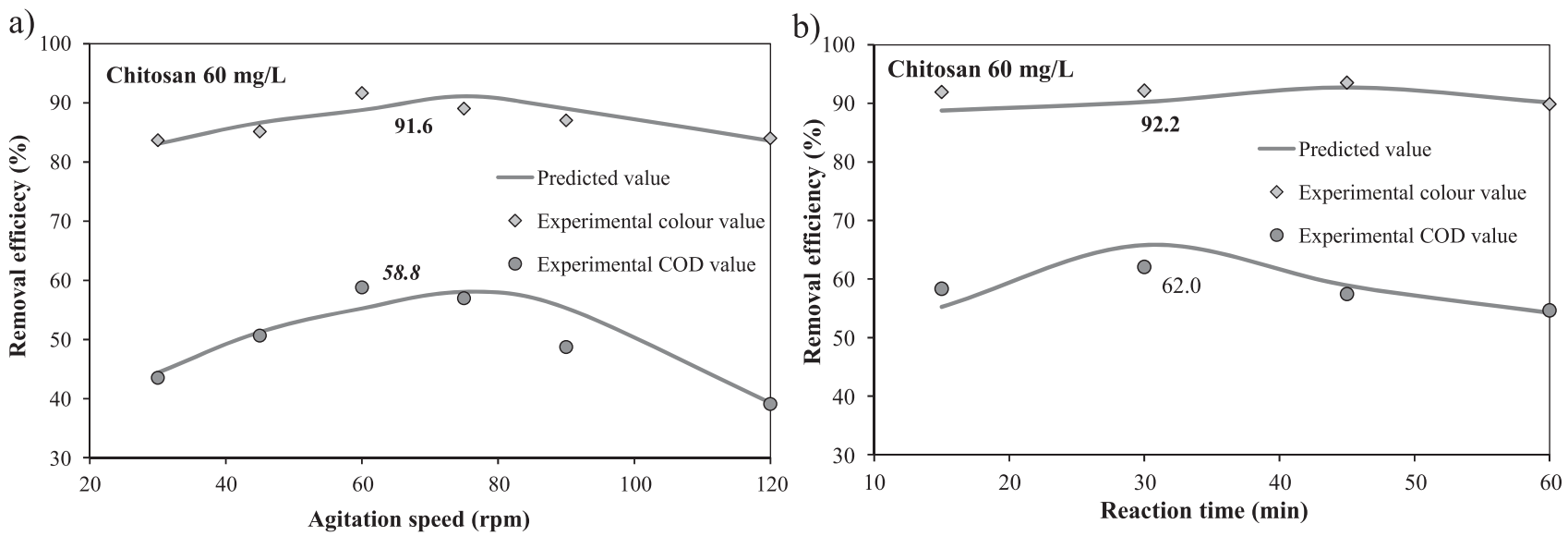

Fig. 7. The influence of: a) agitation speed (IDC $50 \mathrm{mg} / \mathrm{L}, 15 \mathrm{~min}$, and initial $\mathrm{pH}$ 7) and b) reaction time (IDC $50 \mathrm{mg} / \mathrm{L}, 60 \mathrm{rpm}$, and initial $\mathrm{pH}$ 7) on removal efficiencies of the dye using Chitosan. 
a)

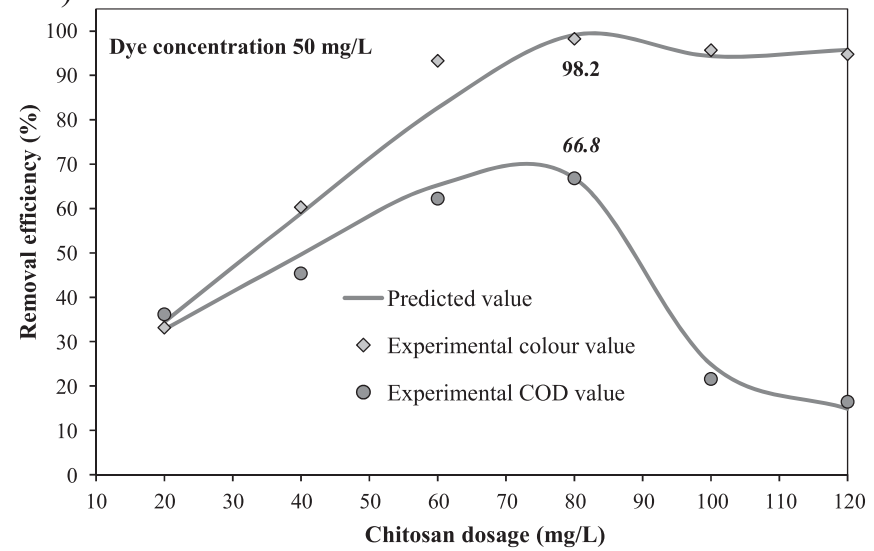

b)

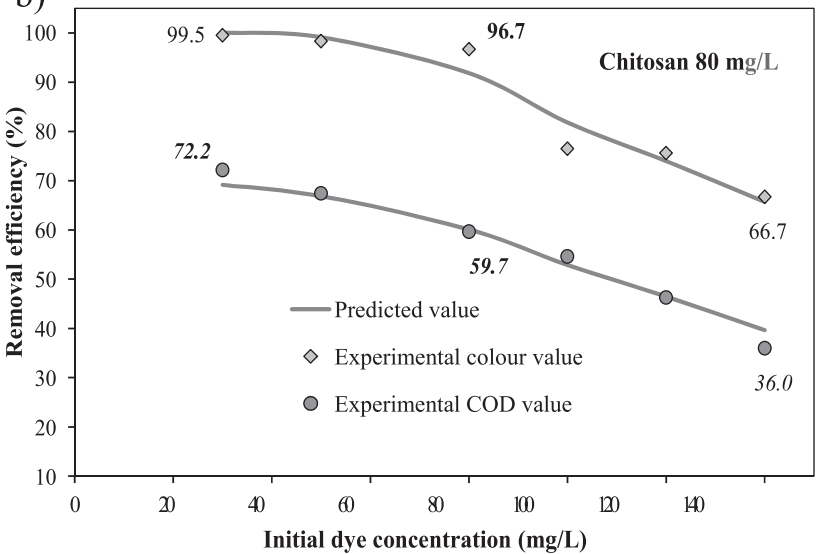

Fig. 8. Influence of: a) chitosan dosage (30 min, $60 \mathrm{rpm}$, and initial $\mathrm{pH}$ 7) and b) dye concentration (30 min, $60 \mathrm{rpm}$, and initial $\mathrm{pH} 7)$ on dye removal efficiencies.

experimental section, chitosan was dissolved in $\mathrm{HCl}$ solvent $(1 \%)$, which could change the $\mathrm{pH}$ of the dye solution. That means the real effect of $\mathrm{pH}$ should be final - not initial $-\mathrm{pH}$. The change of $\mathrm{pH}$ of the dye solution after the treatment process could be presented in Fig. 6. So we consider that this final $\mathrm{pH}$ value matches the earlier research [24] about decolourization of Red 195 by chitosan solution at $\mathrm{pH} 5$. This result may be explained by the great ability of intermolecular force formation between the $\pi$ electron system of the dyes and the hydroxyl and amino groups in chitosan at final $\mathrm{pH} 5$ (corresponding to initial $\mathrm{pH} 7$ ), as compared with other $\mathrm{pH}$ values.

\section{Agitation Speed}

In the Jar-test experiment, an appropriate agitation speed will help contact between particles and coagulants be more efficient and let the coagulation reach optimal efficiency easier. In this study, a range of agitation speeds between 30 and 120 was selected. The results are illustrated in Fig. 7a, which shows the effect of agitation speed on removal efficiencies (COD and colour) for the dye so- lution.

At an agitation speed of $60 \mathrm{rpm}$, colour and COD removal efficiencies were 91.6 and $77.8 \%$, respectively, which was accepted as the optimum agitation speed. The removal efficiencies decreased by increasing agitation speeds. This result is apparently similar to the agitation speed recommended by Aziz [25]. So, this agitation speed was chosen for subsequent experiments.

\section{Reaction Time}

The impact of reaction time on the efficiencies of dye removal was studied by varying time from 15 to $60 \mathrm{~min}$ is shown in Fig $7 b$.

It can be seen that change of reaction time has a minor influence on dye removal efficiencies. Initially, the efficiencies increase together with reaction time until reaction time reached $30 \mathrm{~min}$. From $30 \mathrm{~min}$ on, efficiencies slowly decrease because the formed floc. starts to restabilize. Thus, chitosan interacts less with the dye [26]. So the suitable reaction time for the next experiments is $30 \mathrm{~min}$.

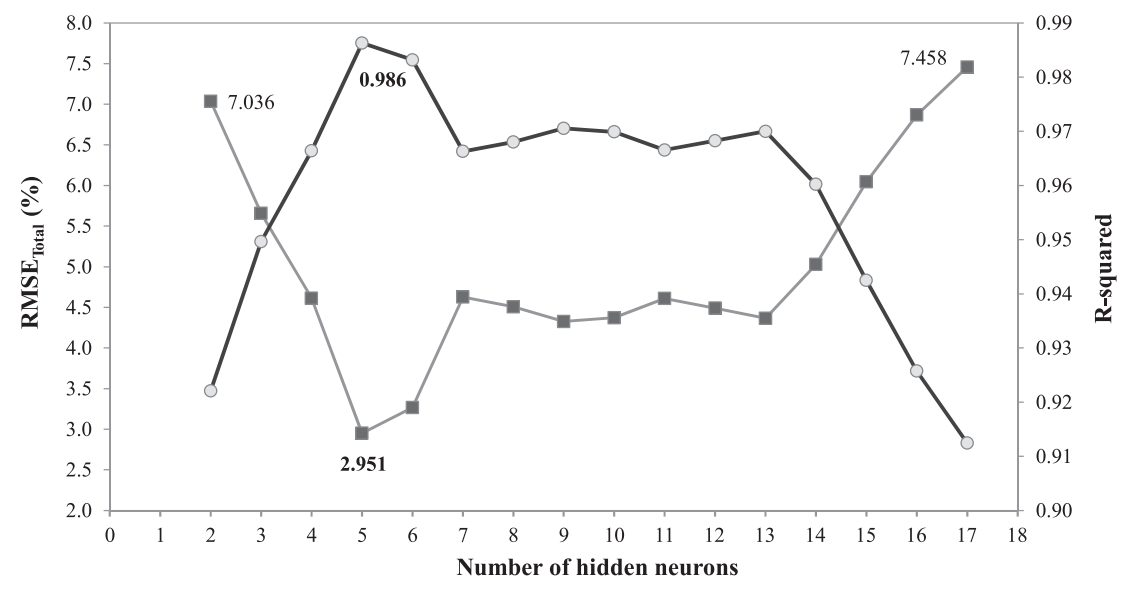

Fig. 9. Influence of the number of hidden neurons on RMSE errors and R-square value. 
Table 2. Observed and predictive values by ANN of chitosan coagulation for dye removal.

\begin{tabular}{|c|c|c|c|c|c|c|c|c|c|}
\hline \multirow{2}{*}{ Run No. } & \multirow{2}{*}{ *IDC $(\mathrm{mg} / \mathrm{L})$} & \multirow{2}{*}{$\mathrm{pH}$} & \multirow{2}{*}{$\begin{array}{c}\mathrm{A} \\
(\mathrm{rpm})\end{array}$} & \multirow{2}{*}{$\begin{array}{c}\mathrm{T} \\
(\mathrm{min})\end{array}$} & \multirow{2}{*}{$\mathrm{C}_{\text {chitosan }}(\mathrm{mg} / \mathrm{L})$} & \multicolumn{2}{|c|}{$\%$ Decolourization } & \multicolumn{2}{|c|}{$\%$ COD removal } \\
\hline & & & & & & Observed & Predicted & Observed & Predicted \\
\hline 1 & 50 & 5.01 & 60 & 15 & 60 & 40.8 & 41.2 & 22.2 & 23.1 \\
\hline 2 & 50 & 7.05 & 60 & 15 & 60 & 91.7 & 89.8 & 59.3 & 56.2 \\
\hline 3 & 50 & 9.04 & 60 & 15 & 60 & 47.0 & 45.6 & 40.7 & 42.1 \\
\hline 4 & 50 & 9.95 & 60 & 15 & 60 & 14.8 & 15.7 & 31.5 & 30.2 \\
\hline 5 & 50 & 10.92 & 60 & 15 & 60 & 15.6 & 16.7 & 28.7 & 32.6 \\
\hline 6 & 50 & 11.64 & 60 & 15 & 60 & 29.3 & 28.2 & 41.7 & 38.6 \\
\hline 7 & 50 & 7.00 & 30 & 15 & 60 & 83.7 & 83.1 & 43.5 & 44.4 \\
\hline 8 & 50 & 7.00 & 45 & 15 & 60 & 85.1 & 86.7 & 50.6 & 51.3 \\
\hline 9 & 50 & 7.00 & 60 & 15 & 60 & 91.6 & 88.8 & 58.8 & 55.2 \\
\hline 10 & 50 & 7.10 & 75 & 15 & 60 & 89.0 & 91.1 & 56.9 & 58.0 \\
\hline 11 & 50 & 7.00 & 90 & 15 & 60 & 87.0 & 89.0 & 48.7 & 55.3 \\
\hline 12 & 50 & 7.00 & 120 & 15 & 60 & 84.0 & 83.6 & 39.1 & 39.3 \\
\hline 13 & 50 & 6.95 & 60 & 15 & 60 & 91.9 & 88.8 & 58.3 & 55.2 \\
\hline 14 & 50 & 7.00 & 60 & 30 & 60 & 92.2 & 90.2 & 62.0 & 65.8 \\
\hline 15 & 50 & 7.06 & 60 & 45 & 60 & 93.5 & 92.7 & 57.4 & 58.9 \\
\hline 16 & 50 & 7.04 & 60 & 60 & 60 & 89.9 & 90.2 & 54.6 & 54.2 \\
\hline 17 & 50 & 7.08 & 60 & 30 & 20 & 33.2 & 34.4 & 36.1 & 32.8 \\
\hline 18 & 50 & 7.04 & 60 & 30 & 40 & 60.3 & 59.0 & 45.3 & 49.6 \\
\hline 19 & 50 & 7.07 & 60 & 30 & 60 & 93.3 & 82.7 & 62.2 & 65.3 \\
\hline 20 & 50 & 7.09 & 60 & 30 & 80 & 98.2 & 99.1 & 66.8 & 66.9 \\
\hline 21 & 50 & 7.04 & 60 & 30 & 100 & 95.7 & 94.3 & 21.6 & 24.9 \\
\hline 22 & 50 & 7.08 & 60 & 30 & 120 & 94.8 & 95.8 & 16.4 & 14.9 \\
\hline 23 & 30 & 7.00 & 60 & 30 & 80 & 99.5 & 100.1 & 72.2 & 69.2 \\
\hline 24 & 50 & 7.10 & 60 & 30 & 80 & 98.3 & 99.1 & 67.4 & 66.9 \\
\hline 25 & 80 & 7.00 & 60 & 30 & 80 & 96.7 & 91.9 & 59.7 & 60.1 \\
\hline 26 & 100 & 7.10 & 60 & 30 & 80 & 76.5 & 81.8 & 54.6 & 52.9 \\
\hline 27 & 120 & 7.00 & 60 & 30 & 80 & 75.6 & 74.0 & 46.3 & 46.5 \\
\hline 28 & 140 & 6.90 & 60 & 30 & 80 & 66.7 & 65.7 & 36.0 & 39.7 \\
\hline
\end{tabular}

$* \mathrm{C}_{\text {chitosan }}$ : chitosan dosage, IDC: initial dye concentration, T: reaction time and A: agitation speed

\section{Chitosan Dosage}

Together with $\mathrm{pH}$, coagulant dosage also plays a relevant role. To investigate the effects of chitosan amount on dye removal, a series of experiments were performed for a wide range of chitosan dosages of $20-120 \mathrm{mg} / \mathrm{L}$.

Fig. 8a shows that the removal efficiencies significantly gain with the increase of chitosan dosage, provided that it is not overdosed ( $>80 \mathrm{mg} / \mathrm{L}$ ). Continuing to increase chitosan dosage in the overdosing range while colour removal is nearly stable causes COD removal to drop. These behaviors can be explained by the ineffectiveness of the overdosed chitosan, i.e., the appropriate dosage of chitosan can cause the dye particles to aggregate (destabilization) and settle, so that chitosan-dye bridging occurs [8]. And when the chitosan dosage in the solution exceeds an optimal threshold, there will not be enough bare dye particles with unoccupied surface available for the attachment of hydroxyl or amino group of chitosan [27]. Moreover, because of the COD in chitosan solution, the excessive chitosan itself makes COD value increase after chitosan is overdosed, hence the drop of COD removal. So those optimal chitosan dosages of $80 \mathrm{mg} / \mathrm{L}$ were chosen for the next series of experiments. 


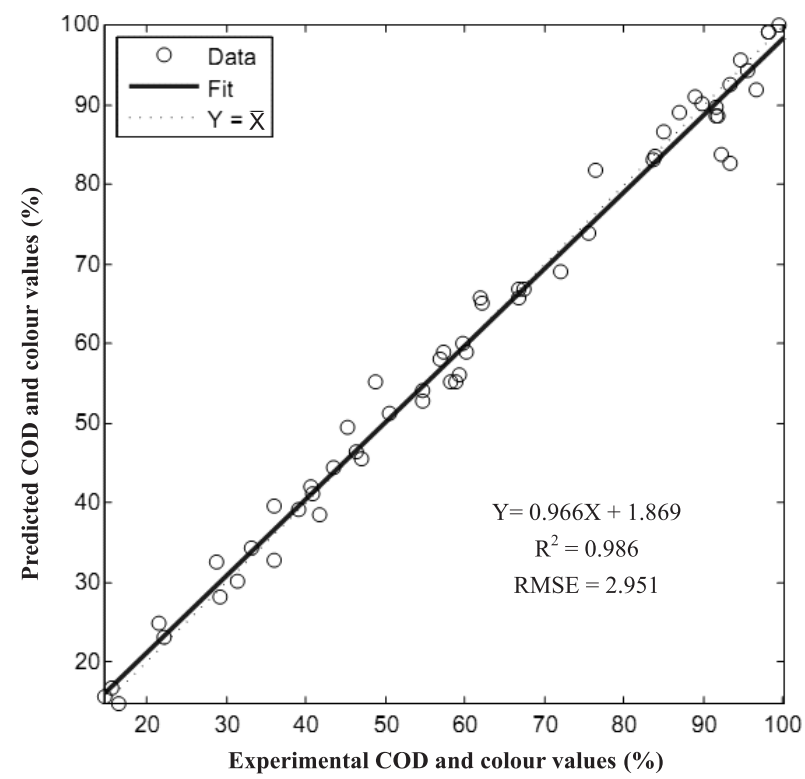

Fig. 10. Comparison between ANN-model predictions and experimental values of the outputs.

\section{Initial Dye Concentration (IDC)}

Several experiments with different initial dye concentrations (IDC) in the range of $30-140 \mathrm{mg} / \mathrm{L}$ were conducted by keeping other parameters constant: optimal $\mathrm{pH}(7)$, agitation speed (60 rpm), chitosan dosage (60 $\mathrm{mg} / \mathrm{L}$ ), and contact time $(30 \mathrm{~min})$. Fig. $8 \mathrm{~b}$ presents the monotonically decreasing trends of dye removal percentage when IDC increases.

These decreases are due to the relatively fixed ratio between chitosan particles and removed dye particles. This ratio is determined by the binding strength between the two kinds of particles [28]. Here, the chitosan dosage is fixed, thus the amount of removed particles was kept nearly unchanged to maintain the ratio, so as IDC decreases, the amount of unremoved particles increases, leading to a decrease of removal efficiencies.

\section{Artificial Neural Network Model}

After training networks with a number of hidden neurons ranging from 2 to 17 (Fig. 9), the optimal topology was determined to be a three-layer feed-forward ANN with five input neurons that correspond to initial $\mathrm{pH}$, reaction time, agitation speed, gum dosage, and initial dye concentration (IDC), five hidden neurons, and two output neurons that correspond to colour and COD removal efficiencies. The performance of the ANN model was estimated by $\mathrm{R}^{2}$ and RMSE values as follows.

\section{Evaluation of ANN Model for the Dye Removal Process}

Table 2 and Fig. 10 shows a comparision between experimental dye removal (colour and COD) values and predicted values using the ANN model. Herein the figure contains two lines: one is the perfect-fit $\mathrm{Y}=\mathrm{X}$ (predicted data $=$ experimental data) and the other is the best fit as indicated by a solid line with the liner equation $\mathrm{Y}=$ $0.966 \mathrm{X}+1.869$, correlation coefficent $\left(\mathrm{R}^{2}\right) 0.986$, and RMSE 2.951. This high value of correlation coefficients shows that the predicted outputs fit measured outputs very well. This value is not exceptional, since the fitness of models for dye processing in aquaeous solution is usually high in previous research, e.g. Arabi [29] reached 0.950 for the prediction of vat Green 1 dye decolourization by nano zero valent Iron, Sadri [10] reached 0.945 for prediction of acid Red 119 decolourization by PAC, and Taheri [30] reached 0.945 for the prediction of acid Black 172 decolourization by the electrocoagulation method using alum electrode, even though they used a complex mathematical method like response surface methodology, which required statistical and experimental knowledge.

Table 3. Contribution of each input factor to output values on the chitosan coagulation process.

\begin{tabular}{|c|c|c|c|c|c|}
\hline Process & Output & Factor & Connection weight & Rank & Influence \\
\hline \multirow{10}{*}{$\begin{array}{l}\text { Chitosan } \\
\text { coagulation }\end{array}$} & \multirow{5}{*}{$\begin{array}{c}\text { Decolourization } \\
\qquad\left(\mathrm{O}_{1}\right)\end{array}$} & Dye con. $\left(I_{1}\right)$ & -0.531 & 2 & negative \\
\hline & & $\mathrm{pH}\left(\mathrm{I}_{2}\right)$ & -0.678 & 1 & negative \\
\hline & & Agitation $\left(\mathrm{I}_{3}\right)$ & -0.427 & 5 & negative \\
\hline & & Time $\left(\mathrm{I}_{4}\right)$ & 0.439 & 4 & positive \\
\hline & & $\mathrm{C}_{\text {chitosan }}\left(\mathrm{I}_{5}\right)$ & 0.525 & 3 & positive \\
\hline & \multirow{5}{*}{$\begin{array}{c}\text { COD removal } \\
\left(\mathrm{O}_{2}\right)\end{array}$} & Dye con. $\left(I_{1}\right)$ & -0.617 & 3 & negative \\
\hline & & $\mathrm{pH}\left(\mathrm{I}_{2}\right)$ & -0.937 & 2 & negative \\
\hline & & Agitation $\left(\mathrm{I}_{3}\right)$ & -0.414 & 4 & negative \\
\hline & & Time $\left(\mathrm{I}_{4}\right)$ & 0.125 & 5 & positive \\
\hline & & $\mathrm{C}_{\text {chitosan }}\left(\mathrm{I}_{5}\right)$ & -3.708 & 1 & negative \\
\hline
\end{tabular}

*Rank of the absolute values 


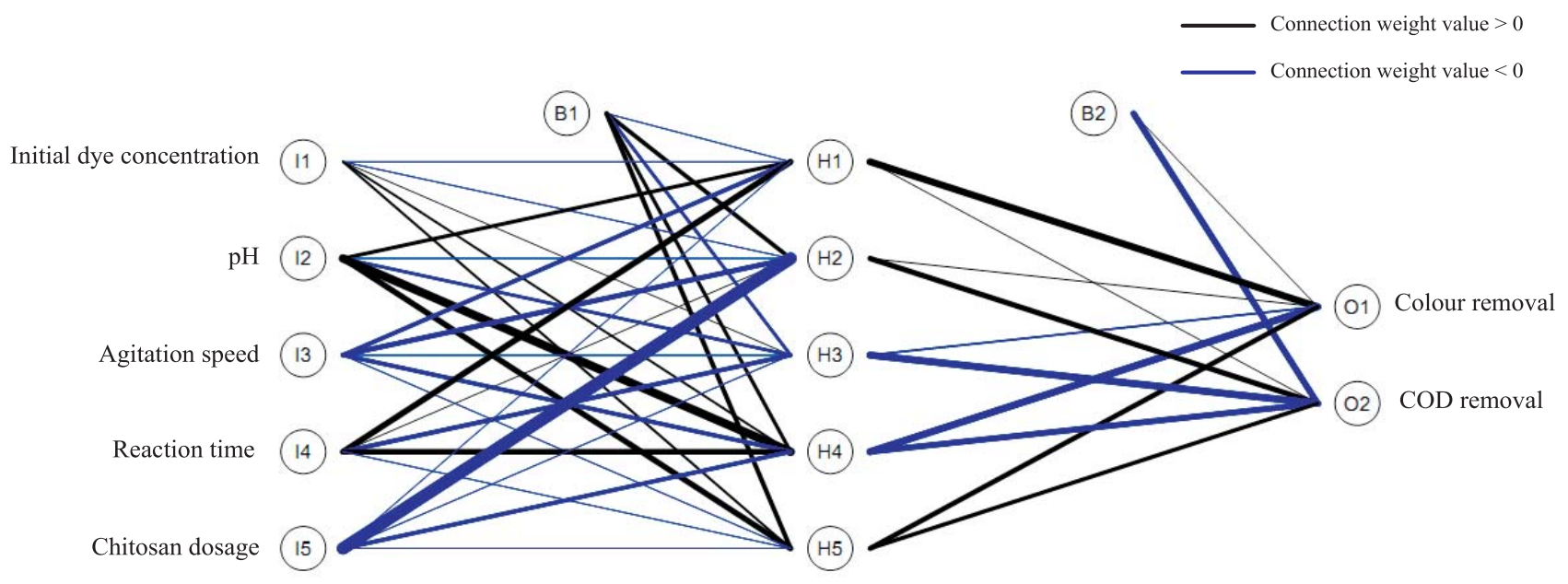

Fig. 11. Neural interpretation plot of red 24 coagulation using chitosan.

Therefore, the neural network modeling effectively simulates and predicts the influential factors of the gum coagulation process.

\section{Interpretation of the ANN Model}

Connection weights algorithms were used to determine the influences of each factor on the outputs presented in Table 3. To evaluate the accuracy of the algorithm, a neural interpretation diagram was also plotted (Fig. 11).

According to Table 3, the two factors of agitation speed $\left(\mathrm{I}_{3}\right)$ and reacion time $\left(\mathrm{I}_{4}\right)$ are least influential on both colour and COD removal processes. The strongly influential factors have strengths $\mathrm{pH}\left(\mathrm{I}_{2}\right)>\mathrm{IDC}\left(\mathrm{I}_{1}\right)>$ $\mathrm{C}_{\text {chitosan }}\left(\mathrm{I}_{5}\right)$ on colour removal $(\mathrm{O} 1)$, and $\mathrm{C}_{\text {chitosan }}\left(\mathrm{I}_{5}\right)>\mathrm{pH}$ $\left(\mathrm{I}_{2}\right)>$ IDC $\left(\mathrm{I}_{1}\right)$ on COD removal $(\mathrm{O} 2)$ processes. Next, we studied the influence of those three factors by analyzing the connections between the three layers in the neural network (I-H-O) shown in Fig. 12 together with the plots of effects of each factor (Figs 4, 8).

- $\mathrm{pH}\left(\mathrm{I}_{2}\right)$ has the most complicated influence. As shown in Fig. 5, pH has a strongly positive effect at low values, then strongly negative effect at mid-range values, and slightly positive effect at high values. Accordingly, Fig. 11 shows two positive influences via $\mathrm{H} 1$ and $\mathrm{H} 5$ (for $\mathrm{O}_{1}$ ) or via $\mathrm{H}_{3}$ and $\mathrm{H}_{5}$ (for $\mathrm{O}_{2}$ ), and a negative influence via $\mathrm{H}_{4}\left(\mathrm{I}_{2}-\mathrm{H}_{4}-\mathrm{O}_{1}, \mathrm{I}_{2}-\mathrm{H}_{4}-\mathrm{O}_{2}\right)$.

- $\mathrm{C}_{\text {chitosan }}\left(\mathrm{I}_{5}\right)$ has a mixture of posivtive and negative influences. The positive effects clearly shown in Fig. $8 \mathrm{a}$ at low dosage rage are modeled by the connections via $\mathrm{H}_{4}$ for both $\mathrm{O}_{1}$ and $\mathrm{O}_{2}$. The negative effects at high dosage range are model by the conections via $\mathrm{H}_{2}$, in which the negative effect on COD removal is especially strong due to the strong $\mathrm{H}_{2}-\mathrm{O}_{2}$ connection.

- IDC $\left(\mathrm{I}_{1}\right)$ has almost all negative influences, which are shown clearly in Fig. 10 and modeled by connections via all four hidden neurons $\mathrm{H}_{1}, \mathrm{H}_{2}, \mathrm{H}_{3}$, and $\mathrm{H}_{4}$. The only positive connections via the $\mathrm{H}_{5}$ model are the flat shape of the plot in Fig. $8 \mathrm{~b}$ at low IDC range.

The network model also shows the combined influences of different factors, e.g. Fig. 12a and Fig. 12b show combined influences of $\mathrm{C}_{\text {chitosan }}$ and IDC on colour

\section{a)}

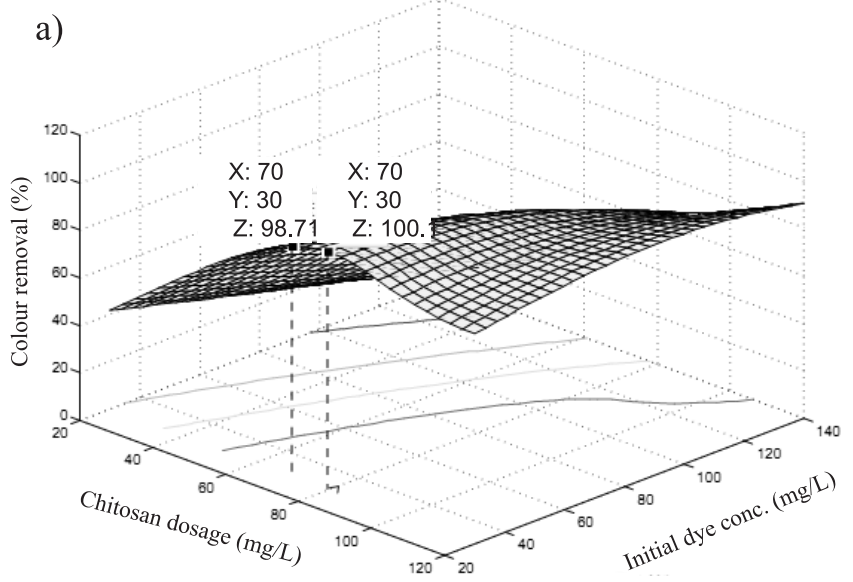

b)

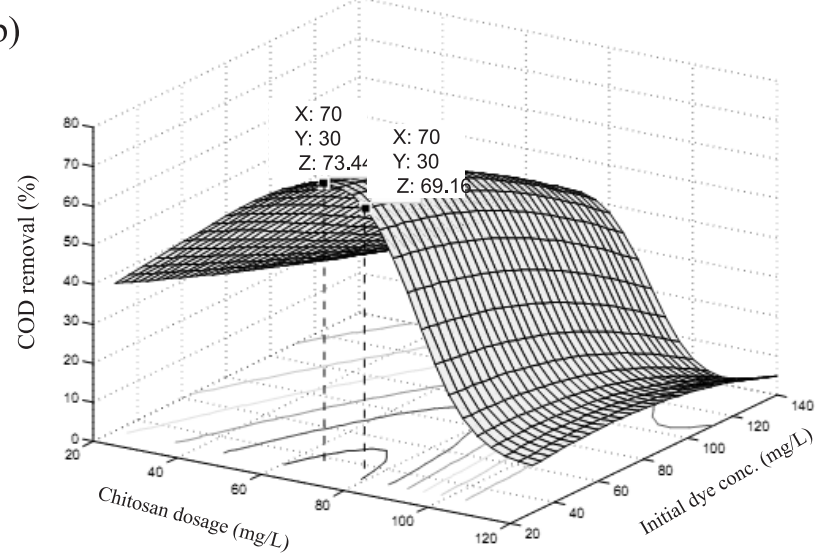

Fig. 12. Response and contour plot of chitosan dosage vs. dye concentration on the removal of: a) colour and b) COD at $30 \mathrm{~min}, 60 \mathrm{rpm}$, and initial $\mathrm{pH} 7$. 
and COD removals, respectively. Looking at the contour lines on those plots, we can clearly see how those factors interact with each other to yield the final results. For example, Fig. 12a shows that colour removal efficiency is unchanged when both $\mathrm{C}_{\text {chitosan }}$ and IDC increase, and in order to improve efficiency, we must increase $\mathrm{C}_{\text {chitosan }}$ while decreasing IDC. Fig 12a also shows that the predicted $100 \%$ optimal efficiency is reached at $\mathrm{C}_{\text {chitosan }}$ $80 \mathrm{mg} / \mathrm{L}$, IDC $30 \mathrm{mg} / \mathrm{L}$. Fig $12 \mathrm{~b}$ shows that $\mathrm{C}_{\text {chitosan }}$ interacts with IDC more complexly in COD removal, and that the optimal efficiency of $73.4 \%$ is predicted to be reached at $\mathrm{C}_{\text {chitosan }} 70 \mathrm{mg} / \mathrm{L}$, IDC $30 \mathrm{mg} / \mathrm{L}$. Those two plots also confirm that the chosen value $\mathrm{C}_{\text {chitosan }} 80 \mathrm{mg} / \mathrm{L}$ is approriate because colour removal has a higher priority than COD removal in our study.

\section{Conclusions}

Chitosan was proven to be an effective coagulant in the removal of reactive vinyl sulfone dye red 24. The best treatment efficiencies for colour and COD reached 99.5 and $72.2 \%$, respectively, using a Jar-test experiment.

The properties of chitosan, the dye, and the sludge form of dye and chitosan were also characterized by FTIR, suggesting that the prepared chitosan had participated in a complex way with the dye. This is evidence that chitosan has the potential for reducing concentrations of reactive dye in aqueous solution.

The three-layer feed-forward ANN implemented in this study has simulated the coagulation process with high precision shown by the determination coefficient $\left(R^{2}\right) 0.986$ and the root mean square error (RMSE) 2.951. This ANN model not only showed the effects of each coagulation factor via sensitivity analysis methods (e.g., the connection weight and neural interpretation diagram used in this study), but also showed the combined influences of different factors via 3D/contour plots. Via sensitivity analysis, the three most influential factors were shown to have strengths $\mathrm{pH}>\mathrm{IDC}>\mathrm{C}_{\text {chitosan }}$ on colour removal and $\mathrm{C}_{\text {chitosan }}>\mathrm{pH}>\mathrm{IDC}$ on COD removal processes. These results prove the applicability of ANN in coagulation modeling and analysis.

\section{References}

1. PERNG Y.-S., BUI H.-M. Decolorization of Reactive Red 195 solution by electrocoagulation process. J. Viet. Env. 5 (1), 22, 2014.

2. SADHASIVAM S., SARITHA E., SAVITHA S., SWAMINATHAN K. Comparison of the Efficacy of Live and Autoclaved Mycelium of Trichoderm harzianum on the Removal of Trypan Blue. Bull. Environ. Contam. Toxicol. 75 (5), 1046, 2005.

3. CHUN H., YIZHONG W. Decolorization and biodegradability of photocatalytic treated azo dyes and wool textile wastewater. Chemosphere. 39 (12), 2107, 1999.

4. VERMA A.K., DASH R.R., BHUNIA P. A review on chemical coagulation/flocculation technologies for removal of colour from textile wastewaters. J. Environ. Manage. 93 (1), 154, 2012.

5. NAYEF Z. A.-M. Coagulant toxicity and effectiveness in a slaughterhouse wastewater treatment plant. Ecotox. Environ. Safe. 65 (1), 74, 2006.

6. ŞENGIL İ. A., ÖZACAR M. The decolorization of C.I. reactive black 5 in aqueous solution by electrocoagulation using sacrificial iron electrodes. J. Hazard. Mater. 161 (2-3), 1369, 2009.

7. DANESHVAR N., KHATAEE A.R., DJAFARZADEH N. The use of artificial neural networks (ANN) for modeling of decolorization of textile dye solution containing C. I. basic yellow 28 by electrocoagulation process. J. Hazard. Mater. 137 (3), 1788, 2006.

8. BLACKBURN R.S. Natural polysaccharides and their interactions with dye molecules: Applications in effluent treatment. Environ. Sci. Technol. 38 (18), 4905, 2004.

9. SINGH V., SETHI R., TIWARI A. Structure elucidation and properties of a non-ionic galactomannan derived from the Cassia pleurocarpa seeds. Int. J. Biol. Macromol. 44 (1), 9, 2009.

10. SADRI M.S., ALAVI M., M R., ARAMI M. Response surface optimization of acid red 119 dye from simulated wastewater using $\mathrm{Al}$ based waterworks sludge and polyaluminium chloride as coagulant. J. Environ. Manage. 92 (4), 1284, 2011

11. KHAYET M., ZAHRIM A.Y., HILAL N. Modelling and optimization of coagulation of highly concentrated industrial grade leather dye by response surface methodology. Chem. Eng. J. 167 (1), 77, 2011.

12. SADRI M., S., ALAVI M., M. R., ARAMI M. Coagulation/ flocculation process for dye removal using sludge from water treatment plant: Optimization through response surface methodology. J. Hazard. Mater. 175, (1-3), 651, 2010.

13. LAMRINI B., BENHAMMOU A., KARAMA A., LANN M.V.A neural network system for modelling of coagulant dosage used in drinking water treatment. In: RIBEIRO B, ALBRECHT R, DOBNIKAR A, PEARSON D, STEELE $\mathrm{N}$, editors; Adaptive and Natural Computing Algorithms: Springer Vienna; 96, 2005.

14. LUYEN V.D. Production, Modifications and Applications of Chitosan in Vietnam. In: GHIGGINO K., editor. Progress in Pacific Polymer Science. 3. Berlin: Springer Berlin Heidelberg; 147, 1994.

15. 1NDABIGENGESERE A., SUBBA N.K. Quality of water treated by coagulation using Moringa oleifera seeds. Water Res. 32 (3), 781, 1998.

16. ELMOLLA E. S., CHAUDHURI M., ELTOUKHY M. M. The use of artificial neural network (ANN) for modeling of COD removal from antibiotic aqueous solution by the Fenton process. J. Hazard. Mater. 179 (1-3), 127, 2010.

17. BRUGNEROTTO J., LIZARDI J., GOYCOOLEA F. M., ARGÜELLES-MONAL W., DESBRIERES J., RINAUDO M. An infrared investigation in relation with chitin and chitosan characterization. Polymer. 42 (8), 3569, 2001.

18. CLESCERI L. ., GREENBERG A.E., EATONA.D. Standard Methods for the Examination of Water and Wastewater. $20^{\text {th }}$ Edition, American Public Health Association, Washington D.C; 1998.

19. SHENG F., ZHU X., WANG W., BAI H., LIU J., WANG P., ZHANG R., HAN L., MU J. Synthesis of novel polyoxometalate $\mathrm{K}_{6} \mathrm{ZrW}_{11} \mathrm{O}_{39} \mathrm{Sn} \cdot 12 \mathrm{H}_{2} \mathrm{O}$ and photocatalytic degradation aqueous azo dye solutions with solar irradiation. J. Mol. Catal. A: Chem. 393, 232, 2014.

20. AHMAD B., BHATTI I.A., HAQ E.U., NAEEM M. Gamma Radiation (137 Cs) induced Degradation, Analytical 
Analysis and Toxicity Studies of vinyl-sulfone based AzoReactive Textile Dyes in Aqueous Solution. Int. J. Chem. 34 (1), 1113, 2013.

21. GOLOB V., VINDER A., SIMONIC M. Effciency of the coagulation/floccula tion method for the treatment of dyebath effluents. Dyes Pigm. 67, (2), 93, 2005.

22. ASSADI A., AMIN M., NATEGHI R. Application of coagulation process reactive blue 19 dye removal from textile industry wastewater. Int. J. Environ. Health Eng. 2 (1), 5, 2013.

23. SANGHI R., BHATTACHARYA B., DIXIT A., SINGH V. Ipomoea dasysperma seed gum: An effective natural coagulant for the decolorization of textile dye solutions. J. Environ. Manage. 81 (1), 36, 2006.

24. WEN Y.Z., LIU W.Q., FANG Z.-H., LIU W.-P. Effects of adsorption interferents on removal of reactive red 195 dye in wastewater by chitosan. J. Environ. Sci. 17 (5), 766, 2005.

25. AZIZ H.A., ALIAS S., ASSARI F., ADLAN M.N. The use of alum, ferric chloride and ferrous sulphate as coagulants in removing suspended solids, colour and COD from semiaerobic landfill leachate at controlled $\mathrm{pH}$. Waste Manage. Res. 25 (6), 556, 2007.
26. KLIMIUK E., FILIPKOWSKA U., LIBECKI B. Coagulation of wastewater containing reactive dyes with the use of polyaluminium chloride (PAC). Pol. J. Environ. Stud. 8 (12), 81, 1999.

27. ANNADURAI G., LING L.Y., LEE J.F. Adsorption of reactive dye from an aqueous solution by chitosan: isotherm, kinetic and thermodynamic analysis. J. Hazard. Mater. 152 (1), 337, 2008.

28. BUTHELEZI S., OLANIRAN A., PILLAY B. Textile dye removal from wastewater effluents using bioflocculants produced by indigenous bacterial isolates. Molecules. 17 (12), 14260, 2012.

29. ARABI S., SOHRABI M.R. Experimental Design and Response Surface Modelling for Optimization of Vat Dye From Water by Nano Zero Valent Iron (NZVI). Acta Chim. Slov. 60 (4), 853, 2014.

30. TAHERI M., MOGHADDAM M., ARAMI M. Optimization of acid black 172 decolorization by electrocoagulation using response surface methodology. Iran. J. Environ. Health. Sci. Eng. 9 (1), 1, 2012. 
